\title{
Effect of forced cooling on the tensile properties and impact toughness of the coarse-grained heat affected zone of a high-strength structural steel
}

\author{
Juhani Laitila ${ }^{1}$, Jari Larkiola ${ }^{2}$, David Porter $^{3}$ \\ Materials and Production Engineering, Faculty of Technology, University of Oulu, \\ Oulu, Finland \\ ${ }^{1}$ Doctoral Candidate, Juhani.Laitila@Oulu.fi \\ ${ }^{2}$ Professor, Jari.Larkiola@Oulu.fi
}

${ }^{3}$ Research Manager, David.Porter@Oulu.fi

\section{Corresponding Author:}

Juhani Laitila, M.Sc (Technology)

University of Oulu

Pentti Kaiteran Katu 1, 90570 Oulu, Finland

Tel: $+358-4477-77419$

Email: Juhani.Laitila@Oulu.fi 


\begin{abstract}
The effects of forced cooling, i.e. forced cooling rate and forced cooling finish temperature, on the tensile and impact toughness properties of simulated weld coarse-grained heat affected zones has been explored in the case of a low-carbon thermomechanically processed steel with a yield strength of $700 \mathrm{MPa}$. The forced cooling finish temperatures that were studied were $400,300,200$ and $100^{\circ} \mathrm{C}$ and the forced cooling rates were 50 and $15{ }^{\circ} \mathrm{C} / \mathrm{s}$. Coarse-grained heat affected zones were simulated using a Gleeble 3800 thermomechanical simulator. For the steel concerned, strength and impact toughness improved significantly when the steel was cooled rapidly to 200 or $100^{\circ} \mathrm{C}$. The results indicate that it may be possible to substantially improve welding productivity by using forced cooling to reduce interpass times.
\end{abstract}

Keywords: Bainite; cooling rate; coarse-grained heat affected zone; high strength steels; welding 


\section{Introduction}

High-strength steels are becoming more commonly used in the engineering and construction industry. By using high-strength structural steels, the structures can be made lighter and more elegant due to thinner wall thicknesses. Furthermore, the financial burden of structural projects can be eased with high-strength steels due to lower overall material costs. However, production time is usually greatly increased because of the need to use more welding passes when high-strength steels are used compared to normal structural steels such as S355. [1-3]

Multipass welding is usually used to achieve sufficiently narrow heat affected zones and sufficiently high cooling rates. The cooling rate has a significant impact on the mechanical properties of the welded joint because it controls the microstructural changes that occur in the steel during welding. Usually steel manufacturers provide recommended weld cooling times between 800 and $500{ }^{\circ} \mathrm{C}(\mathrm{t} 8 / 5)$ along with recommendations about interpass temperatures and heat inputs. The higher the strength the shorter the recommended maximum $t 8 / 5$ time tends to be in order to achieve welds with sufficiently high strength.

In addition, steel producers often provide guidelines for the number of weld passes that should be used to achieve the desired cooling time. For example, SSAB recommends the use of three weld passes for Strenx high strength steels when the material thickness is between 6 and $8 \mathrm{~mm}$ [4]. The required number of weld passes increases as the material thickness increases. This means increased production times due to the time spent waiting for the steel to cool down to the recommended interpass temperature.

Recommended interpass temperatures are around $200-300^{\circ} \mathrm{C}$ when high strength structural steels are used [4-7]. In some cases it can be as high as $400^{\circ} \mathrm{C}$. However, when higher interpass temperature is used, lower heat input is required to avoid exceeding the maximum allowed value of $\mathrm{t} 8 / 5$, which can be counterproductive by leading to the need for additional weld beads. Furthermore, usually with higher interpass temperature the heat affected zone is wider and the allowed heat input is lower, which again increases the number of weld passes required.

Ideally, from a productivity point of view, external cooling should be introduced when welding high strength steel. This would enable the steel to reach the interpass temperature faster. Furthermore, external cooling would allow an increased heat input and the number of weld passes to be reduced. Both of these effects would increase workshop productivity by eliminating a significant amount of the time wasted in the welding process due to waiting in between the weld passes.

It is known that high strength steels that consist of bainite, macte or a mixture of the

two undergo microstructural changes in temperatures below $500^{\circ} \mathrm{C}$ [8]. However, the traditional $t 8 / 5$ has been uniformly used in welding specifications regardless of the material for decades. While it may have been a suitable parameter in the past, with high strength steels becoming more common it may no longer be the optimal choice. 
Instead, the formulation of a new index might be more appropriate and even allow an increase in the productivity of welded high strength steel structures. It is also

proposed in this paper that a new cooling index that measures the time between $800^{\circ}$ $\mathrm{C}$ and the interpass temperature should be used along with the external forced cooling in order to maximize productivity. The reason for this is that microstructural changes

still occur between $500^{\circ} \mathrm{C}$ and the interpass temperature.

In a previous study conducted by Hoy et al. (2015) it was discovered that six different low carbon steels became brittle when they were cooled down to below $300^{\circ} \mathrm{C}$ rapidly [9]. Steels react differently to cooling cycles due to chances in alloying elements and therefore, it is necessary to establish cooling cycles individually on each steel. Other than production time point of view, cooling the steel to temperatures

below $500^{\circ} \mathrm{C}$ rapidly has the potential to produce lower bainitic microstructure. If lower bainite is formed in the weld joint, the strength, toughness and elongation of the joint would be improved compared to what the mechanical properties would be with absence of lower bainite. Lower bainite is able to have similiar strength to that of martensite while having better toughness and elongation, making it the ideal microstructure in the heat affected area (HAZ). [10]

Usually in high strength steel welds, the areas with the lowest strength and lowest toughness are located in the HAZ. In this zone, the base material has not melted, but has undergone microstructural changes because of the thermal cycle imposed on the steel by the heat produced by the welding process. The HAZ can be divided in to four main sub-categories: coarse-grained (CGHAZ), fine-grained (FGHAZ) intercritical (ICHAZ) and subcritical (SCHAZ). These areas are produced by different peak temperatures in the weld. In the case of multipass welding, the CGHAZ of an earlier pass can be heated into the intercritical temperature region producing an intercritically reheated CGHAZ (ICCGHAZ). The CGHAZ can be produced with peak temperature of $1350^{\circ} \mathrm{C}$, while the SCHAZ on the other side of the spectrum can be produced with peak temperature of $600^{\circ} \mathrm{C}$. Regarding fracture toughness, the lowest toughness regions can be the ICCGHAZ, the CGHAZ or the ICHAZ depending on the steel composition. These are known as local brittle zones (LBZ) Regarding tensile strength, the weakest zones tend to be the SCHAZ or ICHAZ. $[11,12]$

Furthermore, another negative side of using multiple weld passes is that every weld pass produces a local brittle zone (LBZ) in the weld. These zones are usually located in the coarse-grained heat affected zone. LBZ has abnormally low fracture toughness. By reducing the required weld passes the amount of these zones are minimized and the risk of fracture happening in the joint is thereby lowered. [13]

This research paper focuses on the effect of the forced cooling finish temperaure (FCFT) and forced cooling rate on the mechanical properties of the CGHAZ due to the fact that it is usually the area with the lowest toughness in a welded joint. If the steel can be forcibly cooled at high speeds directly to the interpass temperature without loss of mechanical properties, significant amounts of time can be saved in the welding process. By eliminating wasted time, the attractiveness of high strength 
structural steels to the construction industry can be increased leading to their wider application.

\section{Experimental procedures}

The experimental part of the research was done with thermocycle simulations in Gleeble 3800 that is used impose thermal cycle on the steel that produces a CGHAZ on the specimens. The test specimens used in the Gleeble tests were cut in longitudinal direction of rolled plates and had the dimension of 10x5x55 mm and 120xØ6 mm. Material used in the tests was Optim 700 MC. The material was chosen due to the materials suitability for the construction industry and having mainly bainite microstructure. [14]

The mechanical properties that were studied were yield and tensile strength, elongation to fracture and impact toughness. Elongation, yield and tensile strength testing were carried out with a Zwick $100 \mathrm{kN}$ testing machine after the Gleeble simulations had been done on the specimens. Charpy V-notch (CVN) tests were carried out as well after the Gleeble simulations according to EN 10045-1 with

$10 \times 5 \times 55 \mathrm{~mm}$ sub-sized specimens at $-40^{\circ} \mathrm{C}$.

\subsection{Test material and specimen preparation}

The steel used in the tests was a commercial grade Optim $700 \mathrm{MC}$ with a thickness of $6 \mathrm{~mm}$. The material was chosen due to its suitability for the construction industry and because it has a mainly bainite microstructure. [14]

Optim $700 \mathrm{MC}$ is a high strength steel with a minimum specified yield strength $\left(R_{p 0.2}\right)$ of $700 \mathrm{MPa}$, a tensile strength $\left(R_{m}\right)$ in the range $750-950 \mathrm{MPa}$, an elongation to fracture $(\mathrm{A})$ of at least $13 \%$ and a specified minimum impact strength of 27 Joules at $-40^{\circ} \mathrm{C}$. The chemical composition of the steel as given by the manufacturer is shown in Table 1. The recommended cooling time t8/5 for Optim 700 $\mathrm{MC}$ is from 5 to 20 seconds. However, if matching weld strength is desired t $8 / 5$ should be $\leq 10$ seconds, according to SSAB [4]. Optim $700 \mathrm{MC}$ has a typical carbon equivalent $(\mathrm{CEV})$ of 0.37 which is associated with good weldability. $(\mathrm{CEV}=\mathrm{C}+$ $\mathrm{Mn} / 6+(\mathrm{Cu}+\mathrm{Ni}) / 15+(\mathrm{Cr}+\mathrm{Mo}+\mathrm{V}) / 5$, where the symbols represent the steel alloy content in wt.\%.) [15]

Table 1: Chemical composition of Optim $700 \mathrm{MC}$, wt.\% [15]

\begin{tabular}{|l|l|l|l|l|l|}
\hline$C \max$ & Si max & Mn max & P max & S max & Al min. \\
\hline 0.10 & 0.20 & 2.10 & 0.020 & 0.010 & 0.015 \\
\hline
\end{tabular}


The specimens were cut from plates by using water jet cutting to avoid changes in the temperature of the steel. After the cutting, samples were machined to fulfil the required tolerance of the standard EN 10045-1 for the Charpy V-notch specimens. The notches for the Charpy V-notch tests were machined following the Gleeble simulation. After testing, ductile fracture percentages were evaluated according to ISO 148-1.

The tensile test specimens were also machined to their final dimension after the Gleeble simulation. Before the simulations the specimens had dimension of $120 \mathrm{x} \emptyset 6$ $\mathrm{mm}$. After the Gleeble simulation, the tensile specimens were machined to have a parallel length of $15 \mathrm{~mm}$ and a nominal thickness of $4 \mathrm{~mm}$. The gauge length of the specimens was $10 \mathrm{~mm}$.

\subsection{Gleeble simulations}

A Gleeble 3800 was used to impose thermal cycles on the steel to simulate the CGHAZs that might be produced by enhancing the cooling rate of welds down to different temperatures followed by cooling in still air. A peak temperature of $1350{ }^{\circ} \mathrm{C}$ was chosen to promote rapid austenite grain growth resulting in a CGHAZ with a low impact and fracture toughness. [16,17]

The test specimens used in the Gleeble tests were cut parallel to the longitudinal rolling direction of rolled plates with dimensions 10x5x55 mm for the Charpy $\mathrm{V}$ impact testing and 120xØ6 mm for the tensile testing.

The specimens were heated to $1350^{\circ} \mathrm{C}$ at $400^{\circ} \mathrm{C} / \mathrm{s}$ where they were held for one second before rapid cooling at 50 or $15^{\circ} \mathrm{C} / \mathrm{s}$. The rapid cooling stage was terminated

at different temperatures, i.e. 500, 400, 300, 200 and $100^{\circ} \mathrm{C}$, after which cooling was continued following the rates given in Table 2, which are representative of the free cooling of a weld in air. Fig. 1 shows examples of two thermal cycles, i.e. where rapid cooling was terminated at 500 or $100^{\circ} \mathrm{C}$.

The low-temperature cooling rates shown in Table 2 were derived from a test conducted by the company Kemppi Oy in Lahti, Finland a T-joint was welded between square structural hollow sections with the dimensions 150x150x8 mm and 100x100x8 mm with a $5 \mathrm{~mm}$ fillet weld using a heat input of $1.5 \mathrm{~kJ} / \mathrm{mm}$. The temperature of the weld was measured down to $100^{\circ} \mathrm{C}$ and formed the basis for the cooling data shown in Table 2. It is worth noting that the measured cooling times were significantly different to times calculated according to the Rosenthal theory. 
Table 2: Simulated air cooling rates

\begin{tabular}{|c|c|}
\hline Temperature range $\left({ }^{\circ} \mathrm{C}\right)$ & Cooling rate $\left({ }^{\circ} \mathrm{C} / \mathrm{s}\right)$ \\
\hline $500-450$ & 7.10 \\
\hline $450-400$ & 5.00 \\
\hline $400-350$ & 3.85 \\
\hline $350-300$ & 2.77 \\
\hline $300-250$ & 2.00 \\
\hline $250-200$ & 1.28 \\
\hline $200-150$ & 0.69 \\
\hline $150-100$ & 0.29 \\
\hline
\end{tabular}

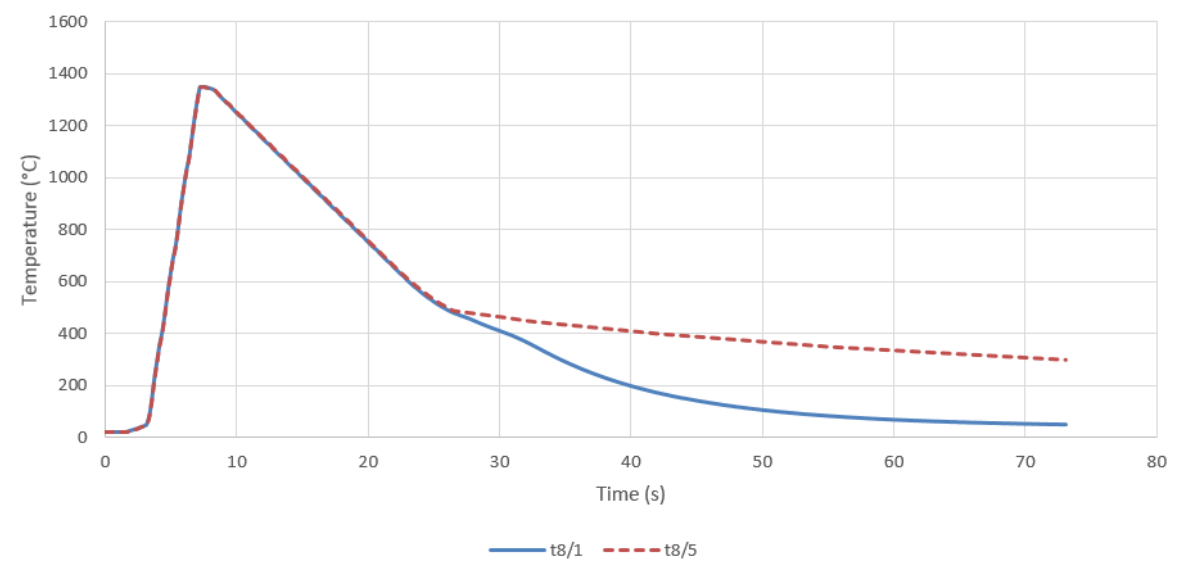

Fig. 1: Thermal cycle with cooling speed of $50^{\circ} \mathrm{C} / \mathrm{s}$ 


\section{Results \& Discussion}

\subsection{Impact Toughness}

Individual absorbed energy and percentage ductile fracture values are shown in Tables 3 and 4, while mean absorbed energy values are shown in Fig. 2 and mean ductile fracture surface percentage in Fig. 3. It can be seen that when the cooling rate was $50^{\circ} \mathrm{C} / \mathrm{s}$ the CGHAZ had similar toughness irrespective of the FCFT. However, when the cooling rate was reduced to $15^{\circ} \mathrm{C} / \mathrm{s}$, there was significant variation between different lower limits of rapid cooling.

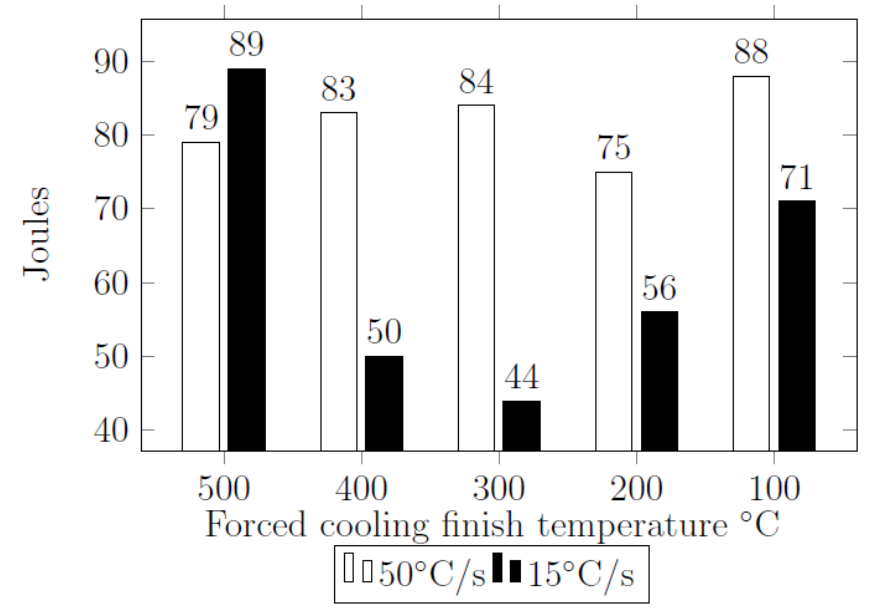

Fig. 2: Toughness of the steel in $-40^{\circ} \mathrm{C}$

Table 3 shows that all of the fracture surfaces were mainly ductile with the faster cooling speed of $50^{\circ} \mathrm{C} / \mathrm{s}$. Therefore, the test temperature of $-40{ }^{\circ} \mathrm{C}$ is usually on or close to the upper shelf of the transition curve. The highest invidual toughness level in this study was achieved with lower limit of rapid cooling of $100^{\circ} \mathrm{C}$ when the cooling speed was $50^{\circ} \mathrm{C} / \mathrm{s}$. 


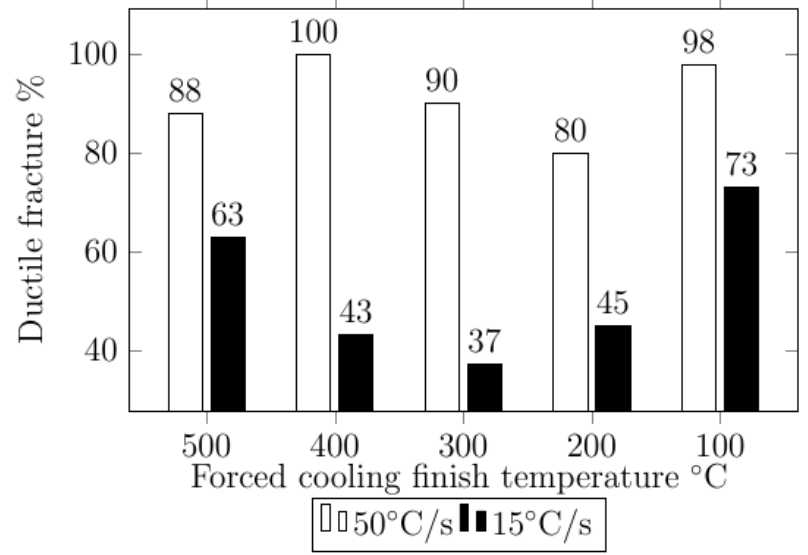

Fig. 3: Percentage of mean ductile fracture at $-40^{\circ} \mathrm{C}$

Table 3. Toughness values and percentage of ductile fracture at $-40^{\circ} \mathrm{C}$ for specimens cooled with $50^{\circ} \mathrm{C} / \mathrm{s}$

\begin{tabular}{|c|c|c|c|c|}
\hline FCFT, ${ }^{\circ} \mathrm{C}$ & $\# 1$ & \#2 & \#3 & Median \\
\hline \multirow{2}{*}{500} & $76 \mathrm{~J}$ & $78 \mathrm{~J}$ & $83 \mathrm{~J}$ & $78 \mathrm{~J}$ \\
\hline & $80 \%$ & $85 \%$ & $100 \%$ & $85 \%$ \\
\hline \multirow{2}{*}{400} & $78 \mathrm{~J}$ & $82 J$ & 90J & $82 J$ \\
\hline & $100 \%$ & $100 \%$ & $100 \%$ & $100 \%$ \\
\hline \multirow{2}{*}{300} & $70 \mathrm{~J}$ & $90.5 \mathrm{~J}$ & $92 \mathrm{~J}$ & $90.5 \mathrm{~J}$ \\
\hline & $80 \%$ & $90 \%$ & $100 \%$ & $90 \%$ \\
\hline \multirow{2}{*}{200} & $74 \mathrm{~J}$ & $75 \mathrm{~J}$ & $77.5 \mathrm{~J}$ & $75 \mathrm{~J}$ \\
\hline & $70 \%$ & $75 \%$ & $95 \%$ & $75 \%$ \\
\hline \multirow{2}{*}{100} & $82 J$ & $82 J$ & $99.5 \mathrm{~J}$ & $82 J$ \\
\hline & $95 \%$ & $100 \%$ & $100 \%$ & $100 \%$ \\
\hline
\end{tabular}


For the slower cooling rate of $15{ }^{\circ} \mathrm{C} / \mathrm{s}$, the test temperature of $-40{ }^{\circ} \mathrm{C}$ is in the ductile - brittle transition temperature range with ductile fracture percentages falling as low as $20 \%$. Now there is a clear effect of FCFT: both absorbed energy and percentage ductile fracture show a minimum when the cooling finish temperature is $300{ }^{\circ} \mathrm{C}$.

Table 4. Toughness values and percentage of ductile fracture at $-40^{\circ} \mathrm{C}$ for specimens cooled with $15^{\circ} \mathrm{C} / \mathrm{s}$

\begin{tabular}{|c|c|c|c|c|}
\hline FCFT, ${ }^{\circ} \mathrm{C}$ & $\# 1$ & \#2 & \#3 & Median \\
\hline \multirow{2}{*}{500} & $73 \mathrm{~J}$ & 92J & $102 J$ & $92 J$ \\
\hline & $60 \%$ & $60 \%$ & $70 \%$ & $60 \%$ \\
\hline \multirow{2}{*}{400} & $11.5 \mathrm{~J}$ & $51 \mathrm{~J}$ & $87 \mathrm{~J}$ & $51 \mathrm{~J}$ \\
\hline & $20 \%$ & $40 \%$ & $70 \%$ & $40 \%$ \\
\hline \multirow{2}{*}{300} & $15.5 \mathrm{~J}$ & $50 \mathrm{~J}$ & $68 \mathrm{~J}$ & $50 \mathrm{~J}$ \\
\hline & $20 \%$ & $40 \%$ & $50 \%$ & $40 \%$ \\
\hline \multirow{2}{*}{200} & $18 \mathrm{~J}$ & 66J & 84J & $66 \mathrm{~J}$ \\
\hline & $20 \%$ & $50 \%$ & $65 \%$ & $50 \%$ \\
\hline \multirow{2}{*}{100} & $14 \mathrm{~J}$ & $92 J$ & 107.5J & $92 \mathrm{~J}$ \\
\hline & $20 \%$ & $100 \%$ & $100 \%$ & $100 \%$ \\
\hline
\end{tabular}

\subsection{Strength}

The strength of the steel was tested with two different cooling rates of $50^{\circ} \mathrm{C} / \mathrm{s}$ and $15^{\circ}$ $\mathrm{C} / \mathrm{s}$. The values shown in Fig. 4 and 5 are the average values of three specimens. Fig. 4 shows that for both forced cooling rates tensile strength at room temperature increases with decreasing FCFT. However, with yield strength this was not the case when the cooling rate was $15^{\circ} \mathrm{C} / \mathrm{s}$. 


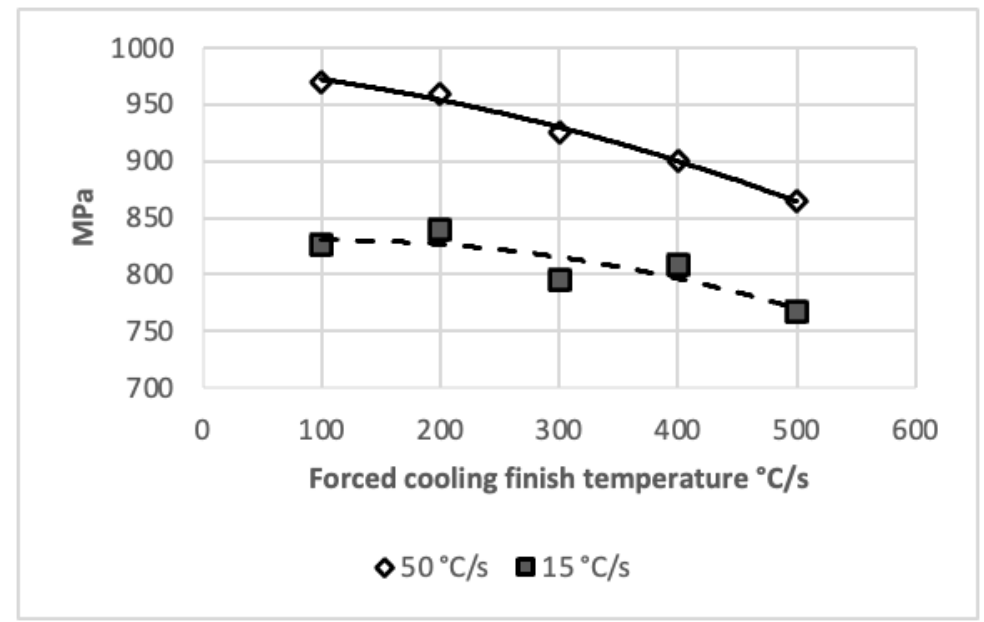

Fig. 4: Tensile strength of the CGHAZ

The increase in tensile strength was $12 \%$ between $500^{\circ} \mathrm{C}$ and $100^{\circ} \mathrm{C}$ with the faster cooling speed of $50^{\circ} \mathrm{C} / \mathrm{s}$ and $8 \%$ with the lower cooling rate of $15^{\circ} \mathrm{C} / \mathrm{s}$. In this study, the greatest increase in tensile strength $9.5 \%$ was observed between $500^{\circ} \mathrm{C}$ and $200^{\circ}$ $\mathrm{C}$, with cooling speed of $15^{\circ} \mathrm{C} / \mathrm{s}$.

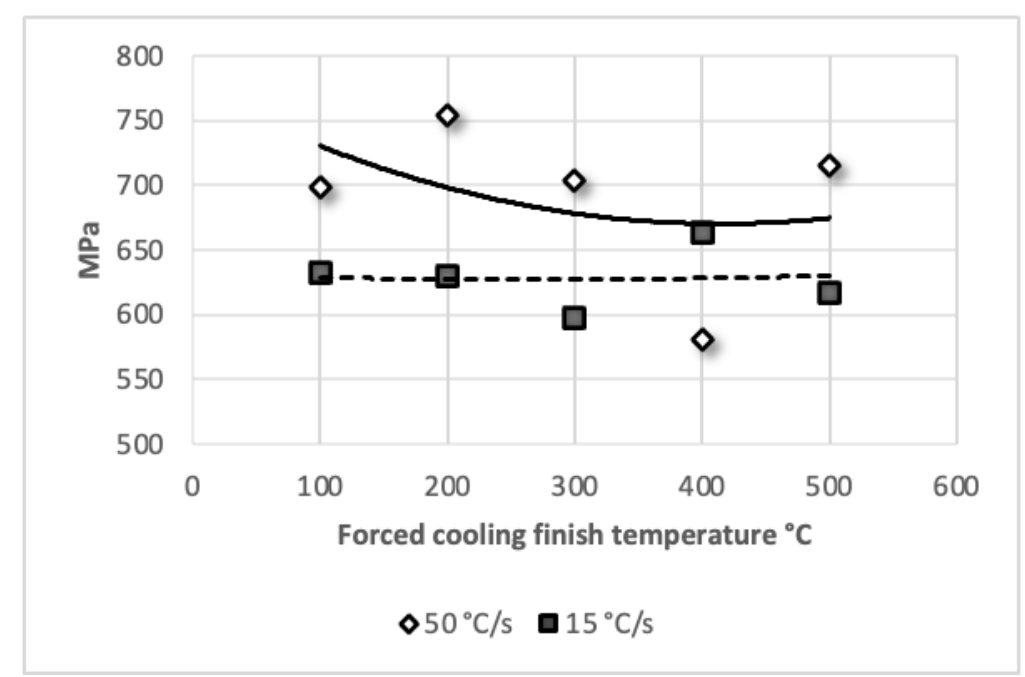

Fig. 5: 0.2\% Yield strength of the CGHAZ 
The highest yield strength values were obtained with the cooling speed of $50^{\circ} \mathrm{C} / \mathrm{s}$ while the lower limit of was $200^{\circ} \mathrm{C}$. With slower cooling speed of $15^{\circ} \mathrm{C} / \mathrm{s}$ the highest yield strength was obtained with lower limit of $400^{\circ} \mathrm{C}$. When the temperature of rapid cooling was 200 or $100^{\circ} \mathrm{C}$ there was no significant decrease of yield strength.

Overall, decreasing the FCFT to $200^{\circ} \mathrm{C}$ or $100^{\circ} \mathrm{C}$ had no detrimental effect on the tensile or yield strength. Furthermore, the Y/T-ratio improved when the lower limit was below $500^{\circ} \mathrm{C}$, except the case of $400^{\circ} \mathrm{C}$ with cooling rate of $15^{\circ} \mathrm{C} / \mathrm{s}$ as can be seen in Fig. 6. The Y/T-ratio improved by $13 \%$ with lower temperature of $100^{\circ} \mathrm{C}$ instead of $500{ }^{\circ} \mathrm{C}$ using the cooling speed of $50{ }^{\circ} \mathrm{C} \%$ s. The improvement was $5 \%$ with a cooling speed of $15^{\circ} \mathrm{C} / \mathrm{s}$.

Based of these results, as the FCFT is decreased the CGHAZ becomes more able to deform before breaking. Of course, these results are only represent the contribution of the CGHAZ. If the same behaviour is applicable to other regions of the HAZ it would be beneficial to the behaviour of the weld as a whole. Higher strength HAZs are able to better resist local necking by contributing to overmatching and thereby shifting deformation during cross-weld overloading towards the base material. This can be very important in various kind of structures, for example if they are located in earthquake prone areas. Lower the Y/T-ratio is, the more plastic deformation the material can tolerate. Furthermore, the Y/T-ratio is important in situations where stress levels above the yield strength are present. $[18,19]$

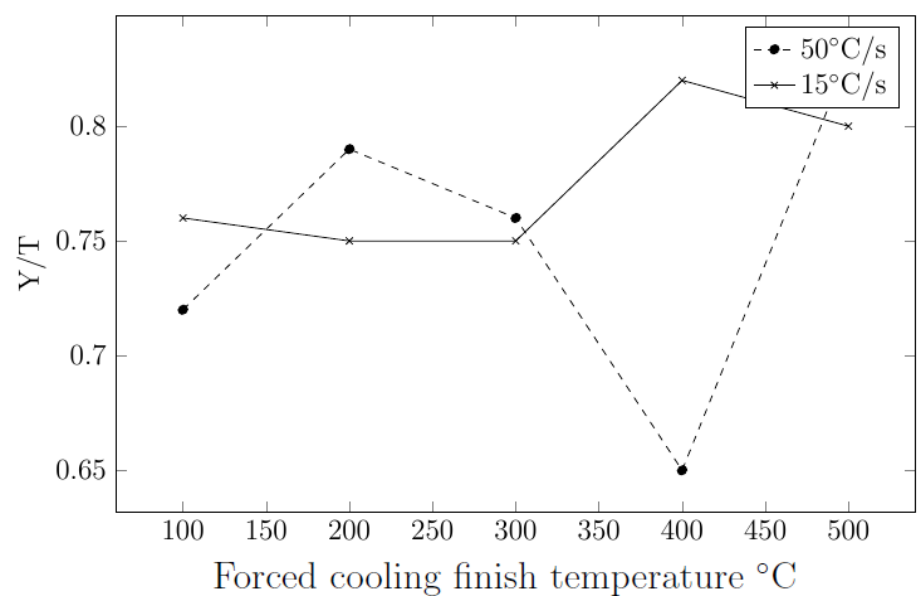

Fig. 6: Y/T Ratios of the steel 


\subsection{Uniform Elongation}

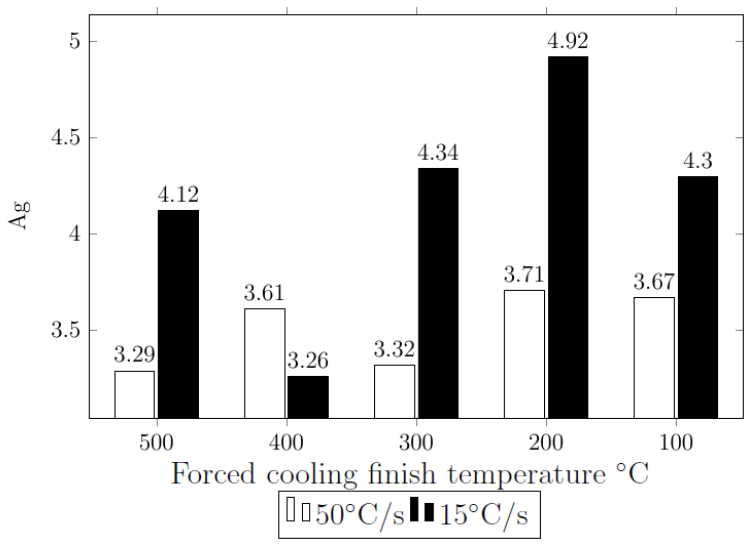

Fig. 7: Elongation of Optim $700 \mathrm{MC}$

As shown in Fig. 7 the uniform elongation of the CGHAZ is clearly improved by reducing the FCFT to low temperatures in the region of $200-100^{\circ} \mathrm{C}$. Usually, the specimens with a lower cooling speed of $15^{\circ} \mathrm{C} / \mathrm{s}$ had better uniform elongation values than the specimens with a cooling speed of $50^{\circ} \mathrm{C} / \mathrm{s}$. The highest elongations values were achieved with lower limit of $200^{\circ} \mathrm{C}$ irrespective of the cooling speed in this study. With cooling speed of $50^{\circ} \mathrm{C} / \mathrm{s}$ the elongation increased by $12.8 \%$ between $500^{\circ}$ $\mathrm{C}$ and $200^{\circ} \mathrm{C}$ and by $11.6 \%$ between lower limits of 500 and $100^{\circ} \mathrm{C}$. With cooling speed of $15^{\circ} \mathrm{C} / \mathrm{s}$ the elongation increased by $19.4 \%$ between $500^{\circ} \mathrm{C}$ and $200^{\circ} \mathrm{C}$ and by $4.4 \%$ between $500^{\circ} \mathrm{C}$ and $100^{\circ} \mathrm{C}$.

\subsection{Microstructure}

Extensive microstructural studies were not undertaken in this study. In general, mechanical properties are, of course, the result of the microstructure that results from the applied processing parameters. One example of the changes that can be brought about by the application of forced cooling to the present steel is shown in Fig. 8, which shows the microstructures of simulated CGHAZs obtained with FCFTs of 500 and $100{ }^{\circ} \mathrm{C}$. The differences are striking, with the lower FCFT showing a much finer bainite lath thickness than the higher FCFT. This is presumably due to the fact that most of the bainite forms at temperatures below $500{ }^{\circ} \mathrm{C}$. With forced cooling to lower temperatures more bainite is formed at lower temperatures where the lath thickness is 
known to be finer [20]. When simulated air cooling starts at $500{ }^{\circ} \mathrm{C}$, more bainite will be able to grow at higher temperatures. In general finer microstructures are associated with higher strengths. However, other factors being equal higher strength will tend to raise the ductile - brittle transition temperature and lower the absorbed energy in the Charpy V test if the test temperature is in the transition temperature range. However, the finer bainite will contain finer carbides that are beneficial to toughness [21]. Transition temperature and absorbed energy are also affected by e.g. the packet size, i.e. effective grain size of the bainitic microstructure [22]. This will depend on the details of the prior austenite grain size and how the bainite packets nucleate and grow. These aspects of the effects of forced cooling would require further investigations.

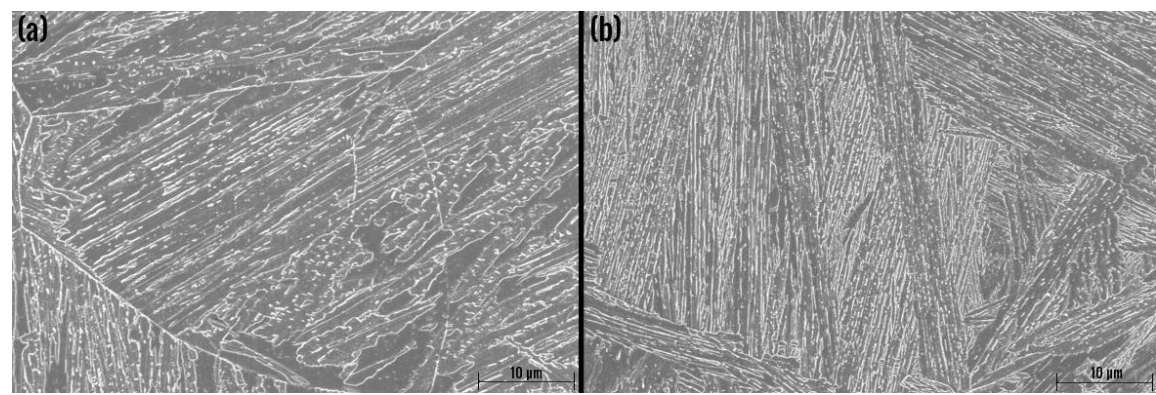

Fig. 8: Microstructure of the simulated CGHAZ with a cooling rate of $50^{\circ} \mathrm{C} / \mathrm{s}$; (a) FCFT $500{ }^{\circ} \mathrm{C}$, (b) FCFT $100{ }^{\circ} \mathrm{C}$

\section{Conclusion}

On the basis of this research concerning the strength and toughness of the CGHAZ in a high-strength thermomechanically processed steel with a yield strength of $700 \mathrm{MPa}$, it appears that, from both a productivity and a mechanical property point of view, it would be beneficial to force cool the welds in such steels down to 100 or $200{ }^{\circ} \mathrm{C}$. There are indications that the refinement of the CGHAZ bainite lath thickness is the reason for the higher strength and impact toughness that can be achieved with a suitable cooling rate.

This has been preliminary research and the work should be continued to consider the properties of other subzones in the HAZ such as the ICHAZ and SCHAZ and to consider other low-carbon thermomechanically processed high strength steels to establish suitable forced cooling rates and forced cooling finish temperatures.

In practice, the challenge will be the forced cooling process itself, because cooling welds down to $100{ }^{\circ} \mathrm{C}$ at a high rate is problematic with the cooling methods currently on the market. 


\section{Acknowledgements}

The Authors acknowledge the help of Jukka Haapio in conducting cooling time experiments on the T-joint welds that were used to provide the cooling time data shown in Table 2. We are grateful to Juha Uusitalo of the University of Oulu for conducting the Gleeble simulations. The authors are grateful for the financial support of Tekes - the Finnish Funding Agency for Innovation within the DIMECC program MANU - Future digital manufacturing technologies and systems.

\section{References}

[1] F. Javidan, A. Heidarpour, X.-L. Zhao, C. R. Hutchinson, J. Minkkinen, Effect of weld on the mechanical properties of high strength and ultra-high strength steel tubes in fabricated hybrid sections, Engineering Structures 118 (2016) 16 - 27. doi: 10.1016/j.engstruct.2016.03.046.

[2] X. Qiang, X. Jiang, F. S. Bijlaard, H. Kolstein, Mechanical properties and design recommendations of very high strength steel $\{960\}$ in fire, Engineering Structures 112 (2016) $60-70$. doi: 10.1016/j.engstruct.2016.01.008.

[3] M. L. Romero, C. Ibaez, A. Espinos, J. Portols, A. Hospitaler, Influence of ultra-high strength concrete on circular concrete-filled dual steel columns, Structures (2016) doi:10.1016/j.istruc.2016.07.001.

[4] SSAB, Welding of strenx, www.ssab.com/Products/Brands/Strenx/Products/Strenx-700-MC!tab=works hop, accessed: 2016-02-03.

[5] L. Lan, X. Kong, C. Qiu, D. Zhao, Influence of microstructural aspects on impact toughness of multi-pass submerged arc welded HSLA steel joints, Materials Design 90 (2016) 488 - 498. doi: 10.1016/j.matdes.2015.10.158.

[6] X.Wang, X.Wang, C. Shang, R. Misra, Characterization of the multi-pass weld metal and the impact of retained austenite obtained through intercritical heat treatment on low temperature toughness, Materials Science and Engineering: A 649 (2016) 282 - 292. Doi: 10.1016/j.msea.2015.09.030.

[7] J. Kim, E. Yoon, Notch position in the HAZ specimen of reactor pressure vessel steel, Journal of Nuclear Materials 257 (3) (1998) 303 - 308. doi: 10.1016/S0022-3115(98)00451-6.

[8] S. Kumar, S. Nath, V. Kumar, Continuous cooling transformation behavior in the weld coarse grained heat affected zone and mechanical properties of nb-microalloyed and HY85 steels, Materials Design 90 (2016) 177 - 184. doi: 10.1016/j.matdes.2015.10.071.

[9] H. K. Sung, D. H. Lee, S. Y. Shin, S. Lee, J. Y. Yoo, B. Hwang, Effect of finish cooling temperature on microstructure and mechanical properties of high-strength bainitic steels containing $\mathrm{cr}$, mo, and b, Materials Science and Engineering: A 624 (2015) 14 - 22. doi: 10.1016/j.msea.2014.11.035.

[10] S. Samanta, P. Biswas, S. Giri, S. B. Singh, S. Kundu, Formation 
of Bainite below the MS temperature: Kinetics and crystallography, Acta Materialia 105 (2016) 390 - 403. doi: 10.1016/j.actamat.2015.12.027.

[11] S. Kim, D. Kang, T.-W. Kim, J. Lee, C. Lee, Fatigue crack growth behavior of the simulated $\{\mathrm{HAZ}\}$ of $800\{\mathrm{MPa}\}$ grade highperformance steel, Materials Science and Engineering: A 528 (6) (2011) 2331 - 2338. doi: 10.1016/j.msea.2010.11.089.

[12] X. wei CHEN, B. LIAO, G. ying QIAO, Y. GU, X. WANG, F. ren XIAO, Effect of $\mathrm{nb}$ on mechanical properties of haz for high-nb x80 pipeline steels, Journal of Iron and Steel Research, International 20 (12) (2013) 53 60. doi: 10.1016/S1006-706X(13)60216-2.

[13] J. il Jang, B.-W. Lee, J.-B. Ju, D. Kwon, W. sik Kim, Experimental analysis of the practical $\{\mathrm{LBZ}\}$ effects on the brittle fracture performance of cryogenic steel $\{\mathrm{HAZs}\}$ with respect to crack arrest toughness near fusion line, Engineering Fracture Mechanics 70 (10) (2003) 1245 - 1257. doi: 10.1016/S0013-7944(02)00111-X.

[14] M. Amraei, T. Skriko, T. Bjrk, X.-L. Zhao, Plastic strain characteristics of butt-welded ultra-high strength steel (uhss), Thin-Walled Structures 109 (2016) 227 - 241. doi: 10.1016/j.tws.2016.09.024.

[15] Optim mc structural steel, http://www.ruukki.com/Steel/Hotrolled-steels/Structural-steels/Optim-MC-structural-steel, accessed: 2016-02-03.

[16] J. T. Bono, J. N. DuPont, D. Jain, S.-I. Baik, D. N. Seidman, Investigation of strength recovery in welds of nucu-140 steel through multipass welding and isothermal post-weld heat treatments, Metallurgical and Materials Transactions A 46 (11) (2015) 5158-5170. doi: 10.1007/s11661-015-3087-x.

[17] H. Xie, L.-X. Du, J. Hu, G.-S. Sun, H.-Y. Wu, R. Misra, Effect of thermo-mechanical cycling on the microstructure and toughness in the weld \{CGHAZ\} of a novel high strength low carbon steel, Materials Science and Engineering: A 639 (2015) 482 - 488. doi: 10.1016/j.msea.2015.05.033.

[18] Effect of Yield-Tensile Ratio on Structural Behavior - High Performance Steels for Bridge Construction, R.L. Brockenbrough Associates, INC., 1995.

[19] A. Bannister, Yield stress/tensile stress ratio: results of experimental programme, British Steel, 1999.

[20] S.B Singh, H.K.D.H Bhadeshia, Estimation of bainite plate-thickness in low-alloy steels, Materials Science and Engineering: A, Volume 245, Issue 1, 1998, Pages 72-79. doi: 10.1016/S0921-5093(97)00701-6.

[21] G. Krauss, Steels: Processing, Structure, and Performance, Second Edition:, Engineering Pro collection, ASM International, 2015

[22] B. Guo, L. Fan, Q. Wang, Fu, Q. Wang, F. Zhang, The role of the bainitic packet in control of impact toughness in a simulated cghaz of x 90 pipeline steel, Metals 6 (11). doi: 10.3390/met6110256. 